\title{
The role of cholesteryl ester transfer protein TaqIB polymorphism in young atherosclerotic heart disease
}

\author{
Bilal Ilanbey', Meral Kayikcioglu², Ebru Demirel Sezer ${ }^{3}$, () Sacide Pehlivan ${ }^{5}$, (i) Ferhan Girgin Sagin ${ }^{3}$, \\ Ferda Ozkinay ${ }^{4}$, (1) Eser Y. Sozmen ${ }^{3}$
}

'Department of Medical Biochemistry, Kırsehir Ahi Evran University, Kirsehir, Turkey

${ }^{2}$ Department of Cardiology, Ege University, Izmir, Turkey

${ }^{3}$ Department of Medical Biochemistry, Ege University, Izmir, Turkey

${ }^{4}$ Department of Medical Genetics, Ege University, Izmir, Turkey

${ }^{5}$ Department of Medical Biology, Istanbul, Turkey

\begin{abstract}
Objectives: There is growing evidence that oxidative modification of low-density lipoprotein (LDL) plays a central role in the pathogenesis of atherosclerosis, which is increasingly seen at younger ages, and that high-density lipoprotein (HDL) levels are inversely associated with the risk of coronary artery disease (CAD). Cholesteryl ester transfer protein (CETP) has a role in the regulation of plasma HDL levels. The most studied polymorphism in the CETP gene is the Taq1B polymorphism, which has consistently been correlated with HDL levels. This case control study of a young ( $<50$ years) Turkish population group with CAD was designed to assess whether there is a relationship between LDL oxidation and CETP Taq1B polymorphism.

Methods: A total of 97 patients with CAD and 43 healthy volunteers were included in the study. Traditional risk factors for CAD (age, gender, smoking, hypertension) were evaluated in the patient group. Oxidative markers of LDL were determined in both groups, as well as routine biochemical parameters. Following DNA extraction from white cells, CETP Taq1B polymorphism was determined using polymerase chain reaction amplification and restriction enzyme digestion. Fragments 174 and $361 \mathrm{bp}$ were identified as B1, and unrestricted $535 \mathrm{bp}$ fragments as B2.

Results: There was no statistical significance between the B1B1, B1B2, B2B2 genotypes in the patient group in terms of body mass index, waist-to-hip ratio, or biochemical parameters. Though the HDL cholesterol levels were higher in the B2B2 genotype, there was no statistically significant difference in comparison with the control group.

Conclusion: The genetic polymorphism of CETP had no significant effect on CETP function and the CETP polymorphism should not be proposed as an independent risk factor for cardiovascular events.

Keywords: Atherosclerosis, cholesteryl ester transfer protein, polymorphism, oxidized low-density lipoprotein
\end{abstract}

A ccording to World Health Organization data, approximately one-fourth of 56.9 million deaths worldwide in 2016 were caused by ischemic heart disease and stroke [1].

It is well established that oxidatively modified low-density lipoprotein (LDL) is an important risk factor for the initiation of atherosclerosis and that high-density lipoprotein (HDL) might play a protective role against coronary artery disease (CAD) [2]. Cholesteryl ester transfer protein (CETP) is mostly bound to HDL in plasma; only $1 \%$ is free [3]. Previously, CETP has been shown to play a part in regulating plasma HDL levels. The role of CETP during the atherosclerotic process is still debated, since it can produce both antiatherogenic and proatherogenic con-

Address for correspondence: Bilal İlanbey, MD. Department of Medical Biochemistry, Kirsehir Ahi Evran University, Kirsehir, Turkey

Phone: +90 5334901307 E-mail: bilal.ilanbey@ahievran.edu.tr ORCID: 0000-0002-7614-281X

Submitted Date: November 05, 2019 Accepted Date: December 30, 2019 Available Online Date: January 27, 2020

${ }^{\circ}$ Copyright 2020 by International Journal of Medical Biochemistry - Available online at www.internationalbiochemistry.com

OPEN ACCESS This work is licensed under a Creative Commons Attribution-NonCommercial 4.0 International License. 
sequences. It is thought to be proatherogenic as a result of transferring cholesteryl esters from HDL to atherogenic lipoproteins, very low-density lipoprotein (VLDL), and LDL, and to be antiatherogenic due to its role in reverse cholesterol transport $[4,5]$. Animal studies have also shown a dual role of CETP with respect to CAD. The introduction of the human CETP gene into apolipoprotein E knock-out mice and LDL receptor knock-out mice resulted in a decrease in HDL levels, leading to increased susceptibility to atherosclerosis, supporting the notion that CETP is proatherogenic $[3,6,7]$. Expression of CETP demonstrated an antiatherosclerotic effect by lowering the VLDL level in transgenic mice expressing human lecithin cholesterol acyltransferase, as well as in a hypertriglyceridemic mouse model, and in mice overexpressing human apolipoprotein CIII [3, 8-10]. Several human studies have also yielded conflicting reports as to whether CETP is proatherogenic, antiatherogenic, or has no relation to atherosclerosis and $\operatorname{CAD}[3,6,11,12]$.

Various mutations and polymorphisms have been identified in the CETP gene; however, the Taq1B polymorphism is one of the most studied. This is a polymorphism at 277 nucleotides at intron 1 in the CETP gene. There are two alleles, B1 and B2 [15]. There have been studies investigating the plasma concentration as well as the activity of CETP and it has consistently been found to be associated with HDL levels [13, 14]. The B2B2 allele has been shown to be closely related to increased HDL levels and decreased CETP levels in normolipidemic subjects $[15,16]$.

This was a case control study designed to investigate any relationship between well-known risk factors, such as oxidizedLDL and paraoxonase (PON) activity, in a young Turkish population with CAD that comprised different genotypes of CETP Taq1B.

\section{Materials and Methods}

A total of 97 patients ( $<50$ years) with angina pectoris, myocardial infarction (MI), and/or a positive exercise test were included in the study, as well as 43 healthy control group participants ( $<50$ years). Blood samples were taken after 8-10 hours of fasting. Plasma and serum were separated immediately after centrifugation and then stored at $-80^{\circ} \mathrm{C}$ until analysis. Whole blood samples were used for DNA isolation.

Serum lipid analyses were performed using standard laboratory methods. PON activity was measured using a previously defined method [17].

\section{LDL isolation and determination of in vitro oxidation of LDL}

Plasma samples were incubated with a precipitating reagent (Merck KGaA, Darmstadt, Germany) for 30 minutes at room temperature [18]. Following centrifugation at $1600 \mathrm{~g}$ for 10 minutes, LDL samples were solubilized with $0.15 \mathrm{~N} \mathrm{NaOH}$. LDL oxidation was determined using thiobarbituric acid reactive substances (TBARS). TBARS was analyzed with TBARS solution and the protein was measured in accordance with Lowry's method [19]. Conjugated diene levels in LDL samples containing $200 \mu \mathrm{gr}$ protein were analyzed with a spectrophotometer by monitoring the absorbance change at a wavelength of 234 $\mathrm{nm}$ at 5 minute intervals for 3 hours and calculations were performed using the extinction coefficient of $29.500 \mathrm{~L} / \mathrm{mol}$ $\mathrm{cm}$. In vitro oxidation of LDL was stimulated with $5 \mu \mathrm{M}$ CuSO4. The conjugation dien peak was measured at the 110th minute after the induction of in vitro oxidation of LDL. TBARS levels were also determined at the same time interval.

\section{CETP Taq polymorphism}

After isolation of genomic DNA from leukocytes using the phenol-ethanol extraction method,CETP geneamplification by polymerase chain reaction (PCR) was performed. Each amplification used 100 ng genomic DNA in a volume of $25 \mu \mathrm{L}$ containing $5 \mathrm{pmol}$ of the primers forward 5'-CACTAGCCCAGAGAGAGGAGTGCC- $3^{\prime}$ and reverse $5^{\prime}$-CTGAGCCCAGCCGCACACTAAC- 3 , and $0.5 \mathrm{mM}$ dNTPs, $1.75 \mathrm{mM} \mathrm{MgCl}, 10 \mathrm{mM}$ Tris, and $0.5 \mathrm{U}$ Taq polymerase. Following denaturation at $94^{\circ} \mathrm{C}$ for 5 minutes, PCR reaction was exposed to 30 cycles $\left(94^{\circ} \mathrm{C}\right.$ for 1 minute, $600 \mathrm{C}$ for 30 seconds, $72^{\circ} \mathrm{C}$ for 45 seconds) and then was finalized with an extension at $72{ }^{\circ} \mathrm{C}$ for 5 minutes. The PCR products were restricted with Taql endonuclease (5U) at $65^{\circ} \mathrm{C}$ for 3 hours. The resulting fragments (174bp and $361 \mathrm{bp}$ ) were visualized with a UV transilluminator following $2 \%$ agarose gel electrophoresis. Fragments 174 and $361 \mathrm{bp}$ were identified as B1, and unrestricted $535 \mathrm{bp}$ fragments as B2.

\section{Statistical analysis}

Statistical analysis was performed using SPSS for Windows, Version 11.0 (SPSS Inc., Chicago, IL, USA). The results were examined using analysis of variance for intergroup comparisons followed by one-way analysis of variance, and the Mann-Whitney $U$ test was used for non-parametric variables. Genotypes and Allelic frequencies were determined by chi-square test. $\mathrm{P}<0.05$ was considered statistically significant.

This study was approved by the Research Ethics Committee of the Medical Faculty of Ege University (No: 05-5.1/2; 2005-05). The study complied with the principles set out in the Helsinki Declaration.

\section{Results}

The baseline characteristics and data related to the oxidantantioxidant status of both groups are summarized in Table 1. The CAD group had more conventional risk factors (smoke, family history, obesity, hypertension). Age $(p<0.01)$ and body mass index $(\mathrm{BMI})$ values $(p<0.01)$ were higher in the patient group than the control group. Additionally, the patients had higher triglyceride $(p<0.01)$ and apolipoprotein $B(A p o-B)$ $(p<0.01)$ levels, and lower HDL $(p<0.01)$ and apolipoprotein $A$ (Apo-A) levels $(p<0.01)$ than the control group. 


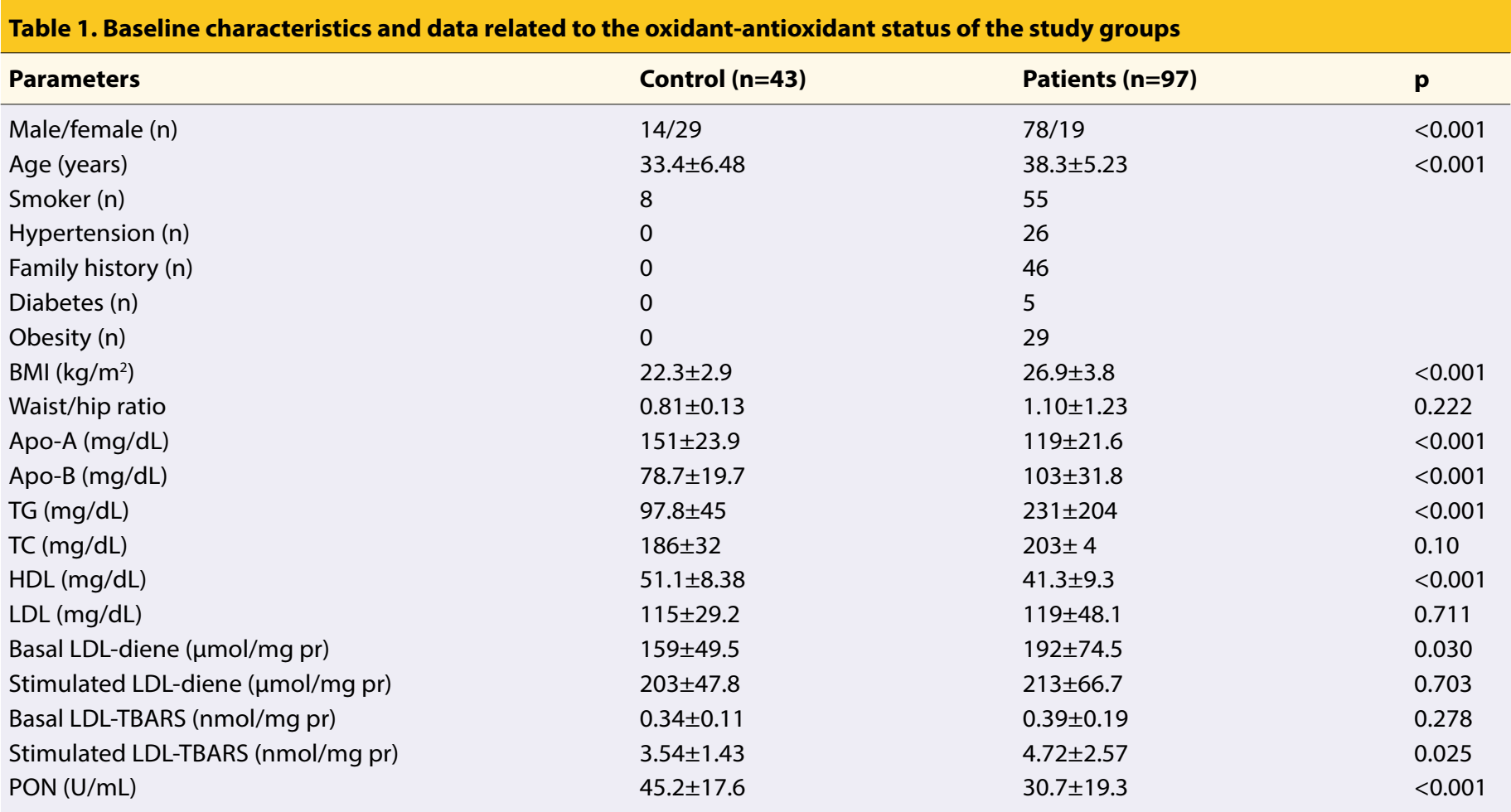

Data are presented as mean \pm SD; Apo-A: Apolipoprotein A; Apo-B: Apolipoprotein B; BMI: Body mass index; HDL: High-density lipoprotein; LDL: Low-density lipoprotein; PON: Paraoxonase; TBARS: Thiobarbituric acid reactive substances; TC: Total cholesterol; TG: Triglyceride.

The antioxidant-oxidant status parameters of the study group are summarized in Table 1. Indicators of LDL oxidation (LDLdiene and TBARS levels, $p<0.01$ and $p<0.05$, respectively) and LDL susceptibility to oxidation (copper-stimulated LDL-TBARS levels, $p<0.01$ ) were higher in the CAD patients compared with the control group. PON activity, an antioxidant parameter, was lower in the patient group.

\section{Genotype frequencies}

The B1B2 genotype frequency was higher in the patient group $(p=0.005$, chisquare test). The genotype distribution of CETP Taq1B gene polymorphism is shown in Table 2. The B1 and B2 allele frequencies were 0.60 and 0.40 , respectively, in the controls and 0.53 and 0.47 in the patients.

When the baseline characteristics and the data related to oxidant-antioxidant status among the genotypes (B1B1, B1B2, and B2B2) were compared in the control group, it was found that only the BMI was higher in subjects with the B2B2 genotype (data not shown). Comparison of the data of baseline characteristics and oxidant-antioxidant status revealed no statistically significant difference in any parameters between genotypes (B1B1, B1B2, B2B2) in the patient group (data not shown). The biochemical parameters of the patients and the controls with the B1B1 genotype are shown in Table 3. The patient group had higher triglyceride levels $(p<0.01)$ and age $(p<0.01)$, and lower HDL $(p<0.01)$ and Apo-A $(p<0.01)$ levels than the control group.

Biochemical analyses of the patients and controls who had the B1B2 genotype are shown in Table 3. The patients had higher
Table 2. Genotype frequencies of CETP Taq1B gene polymorphism in the study groups

\begin{tabular}{lll}
\hline & Control $\mathbf{n}(\%)$ & Patient $\mathbf{n}(\%)$ \\
\hline B1B1 genotype & $17(39.5)$ & $28(28.9)$ \\
B1B2 genotype & $18(41.9)$ & $47(48.5)$ \\
B2B2 genotype & $8(18.6)$ & $22(22.7)$ \\
B1 allele & $52(60.4)$ & $103(53.1)$ \\
B2 allele & $34(39.5)$ & $91(46.9)$
\end{tabular}

triglyceride levels $(p<0.01)$, age $(p<0.01)$, and Apo-B levels $(p<0.01)$, and lower HDL $(p<0.01)$ and Apo-A levels $(p<0.01)$ than the control group. In addition, the patients had higher levels of basal LDL-diene and stimulated LDL-TBARS, which are indicators of LDL oxidation, and lower activity antioxidant parameter PON activity than the control group.

Biochemical analyses of the patients and controls who had the B2B2 genotype are shown in Table 3. The patients had higher triglyceride levels $(p<0.01)$, and lower Apo-A levels $(p<0.01)$ than the control group. In addition, the patients had lower levels of basal LDL-TBARS and PON activity than the control group.

\section{Discussion}

One of the most common causes of death worldwide is atherosclerosis. The incidence of atherosclerosis at a younger age and deaths due to MI have increased with increasing industrialization. 


\begin{tabular}{|c|c|c|c|c|c|c|c|c|c|}
\hline Parameters & $\begin{array}{l}\text { Control } \\
(n=17)\end{array}$ & $\begin{array}{l}\text { Patients } \\
(n=28)\end{array}$ & $\mathbf{p}$ & $\begin{array}{l}\text { Control } \\
(n=18)\end{array}$ & $\begin{array}{l}\text { Patient } \\
(n=47)\end{array}$ & $\mathbf{P}$ & $\begin{array}{l}\text { Control } \\
(n=8)\end{array}$ & $\begin{array}{l}\text { Patient } \\
(n=22)\end{array}$ & $\mathbf{p}$ \\
\hline Age (years) & $33.2 \pm 6.00$ & $39.0 \pm 5.55$ & 0.002 & $31.9 \pm 6.46$ & $37.5 \pm 5.46$ & $<0.001$ & $36.9 \pm 6.93$ & $39.3 \pm 6.34$ & 0.533 \\
\hline $\mathrm{TC}(\mathrm{mg} / \mathrm{dL})$ & $193 \pm 34.3$ & $201 \pm 55.8$ & 0.940 & $179 \pm 29.6$ & $203 \pm 54.7$ & 0.107 & $185 \pm 32.1$ & $206 \pm 53.3$ & 0.177 \\
\hline $\mathrm{HDL}(\mathrm{mg} / \mathrm{dL})$ & $51.4 \pm 8.86$ & $40.8 \pm 9.32$ & $<0.001$ & $51.6 \pm 8.98$ & $40.2 \pm 8.29$ & $<0.001$ & $49.1 \pm 6.12$ & $44.2 \pm 11.1$ & 0.406 \\
\hline LDL (mg/dL) & $121 \pm 30.5$ & $114 \pm 40.5$ & 0.623 & $111 \pm 25.5$ & $122 \pm 54.1$ & 0.522 & $121 \pm 36.7$ & $121 \pm 45.4$ & 0.836 \\
\hline Apo-A (mg/dL) & $151 \pm 29.0$ & $118 \pm 22.9$ & $<0.001$ & $153 \pm 23.2$ & $121 \pm 22.3$ & $<0.001$ & $148 \pm 13.0$ & $120 \pm 19.1$ & 0.002 \\
\hline Apo-B (mg/dL) & $81.7 \pm 21.8$ & $95.5 \pm 32.4$ & 0.291 & $76.1 \pm 18.8$ & $112 \pm 33.4$ & $<0.001$ & $78.7 \pm 19.0$ & $94.8 \pm 22.8$ & 0.131 \\
\hline $\begin{array}{l}\text { Basal LDL-diene } \\
\text { ( } \mu \mathrm{mol} / \mathrm{mg} \mathrm{pr})\end{array}$ & $171 \pm 39.4$ & $189 \pm 60.8$ & 0.462 & $143 \pm 55.8$ & $197 \pm 85.5$ & $<0.001$ & $172 \pm 47.4$ & $187 \pm 67.9$ & 0.961 \\
\hline $\begin{array}{l}\text { Stimulated LDL-TBARS } \\
\text { (nmol/mg pr) }\end{array}$ & $3.93 \pm 1.02$ & $4.54 \pm 1.59$ & 0.991 & $3.38 \pm 1.82$ & $4.69 \pm 2.73$ & 0.018 & $3.12 \pm 1.14$ & $5.01 \pm 3.23$ & 0.051 \\
\hline $\mathrm{PON}(\mathrm{U} / \mathrm{mL})$ & $41.6 \pm 18.0$ & $32.3 \pm 21.7$ & 0.106 & $48.4 \pm 19.8$ & $32.2 \pm 19.3$ & 0.003 & $45.2 \pm 17.6$ & $25.5 \pm 15.5$ & 0.002 \\
\hline
\end{tabular}

Data are presented as mean \pm SD or median (25th-75th percentile). Apo-A: Apolipoprotein A; Apo-B: Apolipoprotein B; BMI: Body mass index; HDL: High-density lipoprotein; LDL: Low-density lipoprotein; PON: Paraoxonase; TBARS: Thiobarbituric acid reactive substances; TC: Total cholesterol; TG: Triglyceride.

Oxidized LDL and low HDL levels play a central role in the development of atherosclerosis. The suggested antioxidant properties of HDL are related to PON as well as Apo-A and platelet activating factor acetylhydrolase. As expected, our study results showed that the conventional risk factors were higher in the CAD group. The lipoprotein profile of the patients was compatible with CAD. Only intermediate-density lipoprotein and LDL particles can enter the subintimal space of the vasculature where the atherosclerotic process begins through modified $\mathrm{LDL}$, and LDL molecules are then absorbed by macrophages [20]. Therefore, LDL and modified LDL molecules, especially oxidized $L D L$, have an important role during the atherosclerotic process. In our study, we examined the ox-LDL levels and the sensitivity of $L D L$ to oxidation in young patients with CAD. The LDL-diene and TBARS levels and the LDL-oxidation sensitivity (copper-induced LDL-TBARS levels) of the patients were higher than those of the control group. Consistent with our data, it has been reported that LDL was more susceptible to oxidation in patients with diabetes mellitus and CAD [21, 22]. In our study, PON activity was lower and the basal LDL-diene level was higher in patients, once again demonstrating the role of PON in preventing LDL oxidation [23].

More genetic studies are being conducted to identify possible genes and polymorphisms in CAD formation. Genome-wide association (GWA) studies have so far found 150 gene loci associated with plasma lipids [24]. Among these genetic variants, ZNF259, CETP, LPA, LPL and PSRC1 have been reported associated with dyslipidemia and CAD [25]. Recently CETP has been shown to play a role in regulating plasma $\mathrm{HDL}$ levels. The presence of $\mathrm{B} 2$ allele has been suggested to be associated with lower plasma CETP concentration, higher HDL-C level. B2 allele frequencies of the individuals in the study were 0.40 in controls and 0.47 in patients. These results are consistent with previous studies in the Turkish population [26-28]. Tanrikulu-Kucuk S et al. [26] reported that B2 allele frequency was 0.46. Yilmaz et al. [27] found that B2 allele frequency was 0.40 . Ozsait et al. [28] reported that B2 allele frequency was 0.43 in men and 0.43 in women. Differences in frequency of the B2 allele was reported in other ethnic groups. B2 allele frequency was found 0.396, 0.40, 0.37, 0.49 in Italy, Chinese, Malaysians and Indians living in Singapore, respectively [29, 30]. Although the distribution of alleles displays similarities between societies, the question of whether certain polymorphisms have more risk for CAD has not yet been clarified.

While the distribution of 3 CETP genotypes in the control group did not demonstrate a statistically significant difference, the B1B2 genotype frequency was 10.536 times higher in our patient group.

In the control group, BMI was found to be higher only in subjects with the B2B2 genotype. There was no significant difference in waist-to-hip ratio, BMl, or other biochemical and oxidant-antioxidant parameters among the 3 genotypes in the patient group.

Patients with the B1B1 allele had higher triglyceride levels with lower HDL and Apo-A levels compared with the control group. There was no significant difference in LDL oxidation products or PON enzyme activity between the patient and the control groups. It may be that high triglyceride levels, especially low HDL and Apo-A levels, are more important than total choles- 
terol and LDL levels with respect to atherosclerosis development in those with the B1B1 genotype.

Patients with $B 1 B 2$ had higher triglyceride, Apo-B, stimulated LDL-TBARS, and basal LDL-diene levels compared with the control group, whereas the levels of HDL, Apo-A and PON activity were lower. It can be concluded that patients in this group are more vulnerable to oxidation and other risk factors.

Patients with the B2B2 polymorphism had high triglyceride levels, low Apo-A and basal LDL-TBARS levels, and low PON activity. PON protects HDL and LDL from oxidation [32] by inhibiting lipid peroxide formation up to $90 \%$ in stimulated LDL [23]. Although HDL levels were higher in those with the B2B2 genotype, there was no significant difference in comparison with the control group (Fig. 1). It has been reported that patients with B2B2 polymorphism had low CETP activity, a high HDL, and a decreased risk of CAD [31]. Freeman et al. [13] observed that high HDL and low CETP activity in normolipidemic subjects with the B2 allele may be caused by environmental factors, such as smoking and alcohol use. It has also been reported that the first Ml occurred later in people with the B2B2 allele [33]. In a meta-analysis, the B2 allele was reported to be a protective factor for ischemic stroke [34]. In a Framingham study group of 1411 males and 1505 females, B1B1 subjects had higher CETP and lower HDL levels than B1B2 or B2B2 individuals, and men with the B2 allele were reported to have a lower risk of developing CAD [14]. This result was thought to be the result of a reduced atherogenic lipid profile in the B2 allele. In an experimental study, the authors reported that cardiovascular mortality decreased by $30 \%$ in B1B2 carriers and by 68\% in B2B2 carriers [35]. Yilmaz et al. [27] found that Ml patients with the B1B1 genotype had lower HDL levels than patients with the B2B2 genotype. They reported that Taq1B polymorphism may be responsible for low HDL levels in both patients and healthy individuals in the Turkish population. In our study, we found that HDL levels in patients with B2B2 genotype were higher than the other two genotypes but it was not statistically significant. This may be due to the low number of the patient groups.

The results of our study revealed that LDL oxidation and oxidative stress indicators were higher in young CAD patients. However, there was no significant difference between the baseline characteristics and oxidant-antioxidant status parameters in CAD patients with different genotypes of CETP Taq1B polymorphism.

\section{Conclusion}

We concluded that the genetic polymorphism of CETP had no significant effect on CETP function and that CETP polymorphism cannot be proposed as an independent risk factor for cardiovascular events.

Acknowledgements: This research was supported by a grant from Ege University Research Foundation (06 TIP 011), Izmir, Turkey.

Conflict of interest: There is no conflict of interest between the authors.

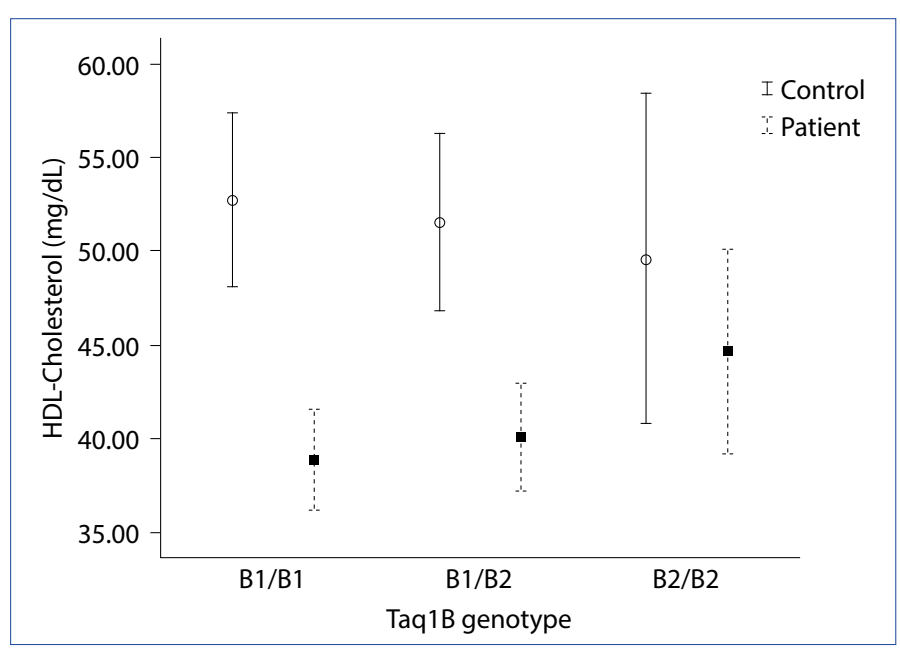

Figure 1. HDL-cholesterol levels in control and patients according to Taq IB polymorphisms.

Ethics Committee Approval: This study was approved by Ege University Faculty of Medicine Clinical Research Ethics Committee (No: 05-5.1/2).

Financial Disclosure: This study was supported by Ege University Scientific Research Projects Unit within the scope of thesis project.

Peer-review: Externally peer-reviewed.

Authorship contributions: Concept - B.I., E.Y.S.; Design - B.I., E.Y.S.; Supervision - M.K., B.I.; Data collection \&/or processing M.K., B.I., E.D.S.; Analysis and/or interpretation - B.I.., S.P., F.F.Ö.; Literature search - B.I., F.G.S., E.Y.S.; Writing - B.I., E.Y.S., E.D.S.; Critical review - F.G.S.

\section{References}

1. https://www.who.int/news-room/fact-sheets/detail/the-top10-causes-of-death. Accessed Oct 2019.

2. Chisolm Steinberg D. The oxidative modification hypothesis of atherogenesis: an overview. Free Radic Biol Med 2000;28:1815-26.

3. Barter PJ, Brewer HB Jr, Chapman MJ, Hennekens $\mathrm{CH}$, Rader DJ, Tall AR. Cholesteryl ester transfer protein: a novel target for raising $\mathrm{HDL}$ and inhibiting atherosclerosis. Arterioscler Thromb Vasc Biol 2003;23:160-7.

4. Inazu A, Koizumi J, Mabuchi H. Cholesteryl ester transfer protein and atherosclerosis. Curr Opin Lipidol 2000;1 1:389-96.

5. de Grooth GJ, Klerkx AH, Stroes ES, Stalenhoef AF, Kastelein JJ, Kuivenhoven JA. A review of CETP and its relation to atherosclerosis. J Lipid Res 2004;45:1967-74.

6. Marotti Castle CK, Boyle TP, Lin AH, Murray RW, Melchior GW. Severe atherosclerosis in transgenic mice expressing simian cholesteryl ester transfer protein. Nature 1993;364:73-5.

7. Plump AS, Masucci-Magoulas L, Bruce $C$, Bisgaier $C L$, Breslow $J \mathrm{~L}$, Tall AR. Increased atherosclerosis in ApoE and LDL receptor gene knock-out mice as a result of human cholesteryl ester transfer protein transgene expression. Arterioscler Thromb Vasc Biol 1999;19:1105-10. 
8. Hayek T, Masucci-Magoulas L, Jiang X, Walsh A, Rubin E, Breslow $\mathrm{J}$, et al. Decreased early atherosclerotic lesions in hypertriglyceridemic mice expressing cholesteryl ester transfer protein transgene. J Clin Invest 1995;96:2071-4.

9. Kako Y, Massé M, Huang LS, Tall AR, Goldberg IJ. Lipoprotein lipase deficiency and CETP in streptozotocin-treated apoB-expressing mice. J Lipid Res 2002;43:872-7.

10. Bérard AM, Föger B, Remaley A, Shamburek R, Vaisman BL, Talley $\mathrm{G}$, et al. High plasma HDL concentrations associated with enhanced atherosclerosis in transgenic mice overexpressing lecithin-cholesteryl acyltransferase. Nat Med 1997;3:744-9.

11. Goto A, Sasai K, Suzuki S, Fukutomi T, Ito S, Matsushita T, et al. Cholesteryl ester transfer protein and atherosclerosis in Japanese subjects: a study based on coronary angiography. Atherosclerosis 2001;159:153-63.

12. Forrester JS, Makkar R, Shah PK. Increasing high-density lipoprotein cholesterol in dyslipidemia by cholesteryl ester transfer protein inhibition: an update for clinicians. Circulation 2005;111:1847-54.

13. Freeman DJ, Griffin BA, Holmes AP, Lindsay GM, Gaffney D, Packard CJ, et al. Regulation of plasma HDL cholesterol and subfraction distribution by genetic and environmental factors. Associations between the Taql B RFLP in the CETP gene and smoking and obesity. Arterioscler Thromb 1994;14:336-44.

14. Ordovas JM, Cupples LA, Corella D, Otvos JD, Osgood D, Martinez $A$, et al. Association of cholesteryl ester transfer protein-TaqIB polymorphism with variations in lipoprotein subclasses and coronary heart disease risk: the Framingham study. Arterioscler Thromb Vasc Biol 2000;20:1323-9.

15. Kuivenhoven JA, de Knijff P, Boer JM, Smalheer HA, Botma GJ, Seidell JC, et al. Heterogeneity at the CETP gene locus. Influence on plasma CETP concentrations and HDL cholesterol levels. Arterioscler Thromb Vasc Biol 1997;17:560-8.

16. Kaman D, İlhan N, İlhan N, Akbulut M. TaqIB and severity of coronary artery disease in the Turkish population: a pilot study. Bosn J Basic Med Sci 2015;15:9-13.

17. Geldmacher-v Mallinckrodt M, Hommel G, Dumbach J. On the genetics of the human serum paraoxonase (EC 3.1.1.2). Hum Genet 1979;50:313-26.

18. Taus M, Ferretti G, Dousset N, Moreau J, Battino M, Solera ML, et al. Susceptibility to in vitro lipid peroxidation of low density lipoproteins and erythrocyte membranes from liver cirrhotic patients. Scand J Clin Lab Invest 1994;54:147-53.

19. Sözmen EY, Sözmen B, Girgin FK, Delen Y, Azarsiz E, Erdener D, et al. Antioxidant enzymes and paraoxonase show a co-activity in preserving low-density lipoprotein from oxidation. Clin Exp Med 2001;1:195-9.

20. Fruchart JC, Nierman MC, Stroes ES, Kastelein JJ, Duriez P. New risk factors for atherosclerosis and patient risk assessment. Circulation 2004;109:III15-9.

21. Regnström J, Nilsson J, Tornvall P, Landou C, Hamsten A. Susceptibility to low-density lipoprotein oxidation and coronary atherosclerosis in man. Lancet. 1992;339:1183-6.

22. Liguori A, Abete P, Hayden JM, Cacciatore F, Rengo F, Ambrosio $\mathrm{G}$, et al. Effect of glycaemic control and age on low-density lipoprotein susceptibility to oxidation in diabetes mellitus type 1. Eur Heart J 2001;22:2075-84.

23. Durrington PN, Mackness B, and Mackness MI. 9. Role of HDL in preventing atherogenic modification of LDL. Atherosclerosis 1999;146:S13.

24. Willer CJ, Schmidt EM, Sengupta S, Peloso GM, Gustafsson S, Kanoni $S$, et al. Discovery and refinement of loci associated with lipid levels. Nat Genet 2013;45:1274-83.

25. Mirhafez SR, Avan A, Khatamianfar S, Ghasemi F, Moohebati $M$, Ebrahimi $M$, et al. There is an association between a genetic polymorphism in the ZNF259 gene involved in lipid metabolism and coronary artery disease. Gene 2019;704:80-5.

26. Tanrikulu-Kucuk S, Ademoglu E, Gurdol F, Bilge AK, MutluTurkoglu U, Nisanci Y. Cholesteryl ester transfer protein Taq1B polymorphism in an angiographically assessed Turkish population: no effects on coronary artery disease risk. Genet Test Mol Biomarkers. 2010;14:637-42.

27. Yilmaz H, Isbir T, Agachan B, Karaali ZE. Effects of cholesterol ester transfer protein Taq1B gene polymorphism on serum lipoprotein levels in Turkish coronary artery disease patients. Cell Biochem Funct 2005;23:23-8.

28. Ozsait B, Kömürcü Bayrak E, Poda M, Can G, Hergenç G, Onat A, et al. CETP TaqIB polymorphism in Turkish adults: association with dyslipidemia and metabolic syndrome. Anadolu Kardiyol Derg 2008;8:324-30.

29. Arca M, Montali A, Ombres D, Battiloro E, Campagna F, Ricci $G$, et al. Lack of association of the common TaqlB polymorphism in the cholesteryl ester transfer protein gene with angiographically assessed coronary atherosclerosis. Clin Genet 2001;60:374-80.

30. Lu Y, Tayebi N, Li H, Saha N, Yang H, Heng CK. Association of CETP Taq1B and $-629 \mathrm{C}>\mathrm{A}$ polymorphisms with coronary artery disease and lipid levels in the multi-ethnic Singaporean population. Lipids Health Dis 2013;12:85.

31. Kuivenhoven JA, Jukema JW, Zwinderman $A H$, de Knijff $P$, McPherson $\mathrm{R}$, Bruschke $\mathrm{AV}$, et al. The role of a common variant of the cholesteryl ester transfer protein gene in the progression of coronary atherosclerosis. The Regression Growth Evaluation Statin Study Group. N Engl J Med 1998;338:86-93.

32. Delattre J, Therond P, Vasson MP, Legrand A, and Rousselett DB. Deleterious vascular effects of oxidized LDL and their modulation by antioxidants. In 20th Espen congress. 1998. Nice, France.

33. Eiriksdottir Bolla MK, Thorsson B, Sigurdsson G, Humphries $\mathrm{SE}$, Gudnason V. The $-629 \mathrm{C}>$ A polymorphism in the CETP gene does not explain the association of TaqIB polymorphism with risk and age of myocardial infarction in Icelandic men. Atherosclerosis 2001;159:187-92.

34. Yu DD, Ren QQ, Dong B, Zhao DD, Sun YH. Effect of Cholesteryl Ester Transfer Protein Gene TaqIB Polymorphism on the Risk of Ischemic Stroke: A Meta-Analysis. J Stroke Cerebrovasc Dis 2017;26:2354-61.

35. Carlquist JF, Muhlestein JB, Horne BD, Hart NI, Bair TL, Molhuizen $\mathrm{HO}$, et al. The cholesteryl ester transfer protein Taq1B gene polymorphism predicts clinical benefit of statin therapy in patients with significant coronary artery disease. Am Heart J 2003;146:1007-14. 